\title{
Review
}

\section{Innate apoptotic immunity: the calming touch of death}

\author{
RB Birge ${ }^{1}$ and DS Ucker ${ }^{\star, 2}$
}

\begin{abstract}
Apoptotic cell death is an essential and highly ordered process that contributes to both the development and the homeostasis of multicellular organisms. It is associated with dramatic biochemical and cell biological events within the dying cell, including fragmentation of the nucleus and the redistribution of intracellular proteins and membrane lipids. It has long been apparent that phagocytic clearance of the cell corpse is an integral part of the apoptotic process; apoptotic clearance also may be essential in tissue homeostasis. During the cell death process, apoptotic cells acquire new cell surface determinants for specific recognition by responder phagocytes and suppression of immune responsiveness. Recent studies indicate that these determinants are well conserved throughout metazoan evolution; remarkably, their recognition shows no species-specific restriction. Professional and non-professional phagocytes recognize and respond to apoptotic cells similarly, notably with the immediate-early transcriptional repression of a variety of specific genes including those encoding inflammatory cytokines. Secondary responses following engulfment of the apoptotic corpse, utilizing several distinct mechanisms, enhance and sustain this apoptotic suppression. In this review, we highlight the central role of apoptotic cells in innate homeostatic regulation of immunity. Cell Death and Differentiation (2008) 15, 1096-1102; doi:10.1038/cdd.2008.58; published online 2 May 2008
\end{abstract}

\section{The Specific Recognition of Apoptotic Cells Engages Innate Immunosuppressive Responsiveness}

The phenomenon of physiological cell death was first observed in the 1880s in studies of normal metazoan development and metamorphosis. ${ }^{1}$ Already then, it was recognized that the process of cell death - what we know today as apoptosis - was intimately tied to the elimination of those corpses by phagocytic cells. At about the same time, Metchnikoff ${ }^{2}$ described the process of phagocytosis, involving primarily microphages (neutrophils) and macrophages, by which bacterial pathogens were eliminated. Not surprisingly, that process was associated generally with inflammation.

In contrast, a most striking aspect of the process of apoptotic cell death is targeted elimination without inflammation or tissue scarring. ${ }^{3}$ This behavior was beautifully exemplified in studies examining the clearance of neutrophils, which are abundant and short-lived inflammatory effectors. When activated, neutrophils secrete inflammatory cytokines and chemokines, and release a variety of distinct effector molecules, including matrix metalloproteinases and other proteases, complexes that generate reactive oxygen and nitrogen intermediates, and other antimicrobial proteins. Morphological studies indicated that the granular contents of neutrophils are not released when those cells die apoptotically. ${ }^{4}$ Moreover, apoptotic neutrophils do not trigger the release of inflammatory mediators (including chemokines and cytokines) from engulfing macrophages. ${ }^{5-7}$ These results encouraged the notion that prompt clearance and the prevention of cellular leakage is an important aspect of apoptotic cell death and a key to the avoidance of inflammation. Up to $10^{11}$ apoptotic neutrophils are cleared in a human adult each day, so the recognition and clearance of dead cells must be rapid and efficient. In this view, the quintessential element of apoptosis might be the generation of cellular markers for phagocytic recognition.

Further work broadened this view to reveal that the absence of inflammatory mediator release associated with apoptotic cell clearance is more than the passive avoidance of inflammation. Apoptotic neutrophils, like all other apoptotic cells, are potently and affirmatively immunosuppressive. ${ }^{6,8,9}$ This immunosuppressive effect is not mediated by soluble factors released from the dying cells. Rather, during the cell death process, apoptotic cells acquire surface determinants that trigger anti-inflammatory responses in macrophages. ${ }^{8}$ For example, while stimulation of macrophages via any of the innate immune receptors for so-called pathogen-associated molecular patterns (PAMPs) leads to the robust secretion of inflammatory cytokines, interactions with apoptotic cells potently attenuate these responses. ${ }^{6,8-11}$ More than simply tagging cells for phagocytic clearance, then, the critical recognition molecules that mark the apoptotic cell actually

\footnotetext{
${ }^{1}$ Department of Biochemistry and Molecular Biology. UMDNJ-New Jersey Medical School, MSB E-647, 185 South Orange Avenue, Newark, NJ 07103, USA and 2Department of Microbiology and Immunology, University of Illinois College of Medicine, MSB E803 (MC 790), 835 South Wolcott, Chicago, IL 60612, USA ${ }^{*}$ Corresponding author: DS Ucker, Department of Microbiology and Immunology (MC 790), University of Illinois College of Medicine, 835 South Wolcott, Chicago, IL 60612, USA. Tel: 312413 1102; Fax: 312413 7385; E-mail: duck@uic.edu

Keywords: apoptosis; autoimmunity; innate immunity; phagocytosis; signal transduction; transcriptional repression

Abbreviations: Del1, developmental endothelial locus-1; ERK, extracellular signal-regulated kinase; Gas6, growth arrest-specific factor-6; HMGB1, high-mobility group box 1; IFN, interferon; IL, interleukin; JNK, Jun N-terminal kinase; LPS, lipopolysaccharide; MFG-E8, milk fat globule-epidermal growth factor 8 ; NF $\kappa B$, nuclear factor- $\kappa B$; PAMP, pathogen-associated molecular pattern; SOCS, suppressor of cytokine synthesis; STAT, signal transducer and activator of transcription; TNF $\alpha$, tumor necrosis factor- $\alpha$; TAM, Tyro3/Ax//Mer

Received 12.3.08; revised 25.3.08; accepted 25.3.08; Edited by G Melino; published online 02.5.08
} 
are determinants of innate immunosuppression. This distinction is reinforced by the observation that apoptotic immunosuppression can be dissociated from phagocytosis. Apoptotic cells bind to macrophages in a saturable, receptor-mediated process $^{8}$ and the blockade of engulfment has no effect on apoptotic cell binding or on the triggering of apoptotic suppression. ${ }^{10}$ Thus, the apoptotic cell surface determinants that trigger suppression and that assure engulfment may be distinct.

While numerous studies have explored the variety of deathassociated markers displayed by apoptotic cells, the functional characterizations of these molecules have focused on engulfment (and not immunosuppression) as an experimental end point. Understanding the defining molecular signatures of apoptotic cell death, and the signaling pathways and mechanisms by which they effect immunosuppression, remains a challenging and elusive biological problem.

\section{Immediate-Early Transcriptional Repression is the Primary Mechanism of Immunosuppression Exerted by Apoptotic Cell Recognition}

The apoptotic suppression of inflammatory responsiveness is effected primarily at the level of specific transcriptional initiation. ${ }^{10}$ Cytokines and chemokines are involved centrally in the inflammatory responses elicited by pathogens and other innate immune agonists, and expression of these factors, in many cases, is regulated directly at the level of transcription following the activation of relevant transcriptional activators, including nuclear factor- $\kappa \mathrm{B}(\mathrm{NF} \kappa \mathrm{B}) .^{12}$ Quantitative reverse transcriptase-polymerase chain reaction analysis of the levels of a number of inflammatory cytokine and chemokine gene transcripts in macrophages confirmed that stimulation with bacterial lipopolysaccharide (LPS, a PAMP of Gram-negative bacteria) results in their rapid upregulation, and revealed that apoptotic cell interactions trigger an equally rapid blockade (or reversal) of that induction. ${ }^{10}$ The inhibition of secretion of these factors, including interleukin (IL)-6, IL-8, tumor necrosis factor- $\alpha$ (TNF $\alpha)$, and macrophage inflammatory protein $-1 \alpha$, by apoptotic cells follows this more rapid transcriptional repression. $8,10,11$ Like the induction of cytokine gene expression following PAMP stimulation, the transcriptional repression induced by apoptotic cells is an immediate-early response that occurs in the absence of de novo protein synthesis, ${ }^{10}$ suggesting the existence of a distinct signal transduction pathway leading from innate apoptotic recognition to transcriptional repression (Figure 1).

Studies using transcriptional reporter constructs have been revealing of the mechanism of apoptotic suppression. Cvetanovic and co-workers ${ }^{10,11}$ found that luciferase activity from an IL-8 gene promoter driving expression of a heterologous firefly luciferase gene transfected into macrophage cells was induced by innate agonists and repressed specifically by apoptotic targets. Similarly, a synthetic construct composed of a basal transcriptional promoter fused to an oligomerized $\mathrm{NF}_{\kappa} \mathrm{B}$-binding motif was responsive to apoptotic repression. Surprisingly though, specific transcriptional activators, including $\mathrm{NF}_{\kappa} \mathrm{B}$, are not the targets of apoptotic regulation. ${ }^{10,11}$ The activation of $\mathrm{NF}_{\kappa} \mathrm{B}$ upon PAMP stimulation, including degradation of its inhibitor $I_{\kappa} \mathrm{B} \alpha$, is unimpaired

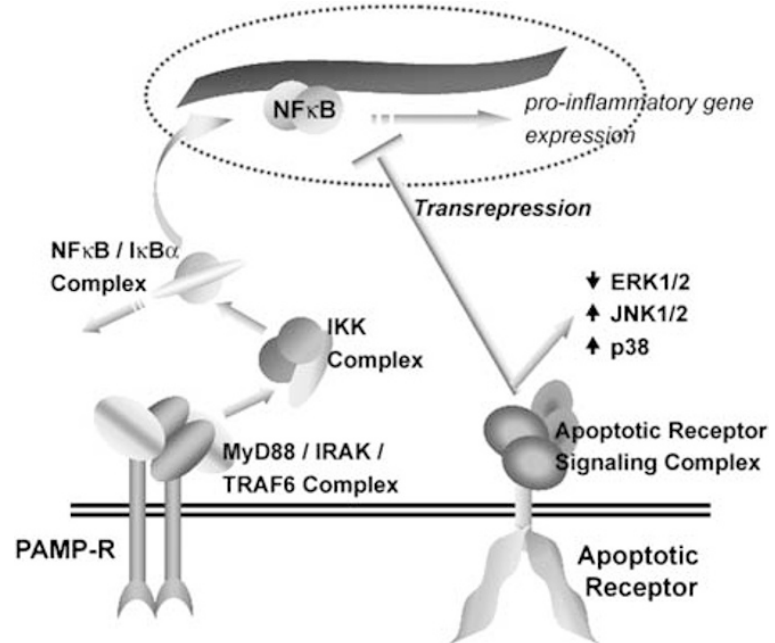

Figure 1 Primary signaling events involved in initiating apoptotic suppression. Specific recognition of apoptotic cells, independent of engulfment, triggers immunosuppression. As illustrated here, the immediate-early repression of inflammatory cytokine gene transcription follows directly from specific apoptotic recognition. Apoptotic recognition, via one or more presumptive innate apoptotic receptors, does not affect proximal signaling triggered by PAMP recognition. For example, the activation of $\mathrm{NF}_{\kappa} \mathrm{B}$, a transcriptional activator essential for proinflammatory cytokine gene expression, ensues upon triggering of a PAMP receptor (PAMP-R, such as the LPS-responsive Toll-like receptor 4$){ }^{12} \mathrm{NF}_{\kappa} \mathrm{B}$ activation depends on the function of molecules closely associated with the PAMP-R, such as the MyD88 adaptor and IRAK and TRAF6 kinases, as well as the downstream IKK kinase complex involved in the inactivating phosphorylation of the $\mathrm{NF} \kappa \mathrm{B}$ inhibitor $\mid \kappa \mathrm{B} \alpha$. On the contrary, apoptotic recognition engages distinct signaling events, presumably through a specific receptor-associated signaling complex. Proximal signaling responses include the activation of JNK1/2 and p38, and the inhibition of ERK1/2 activation. ${ }^{16,36}$ Additional transrepressive factors, such as the peroxisome proliferator-activated receptor $-\gamma$, might also be activated, leading to selective transcriptional repression of inflammatory cytokine genes. An obligate relationship among these multiple events has not been established. Most importantly, the identities of specific recognition determinants on apoptotic cells and their corresponding receptors remain to be elucidated

in the presence of apoptotic targets, ${ }^{10,13}$ and apoptotic repression of the IL-8 promoter is unaffected by deletion of its cognate $\mathrm{NF}_{\kappa} \mathrm{B}$-binding sequence. ${ }^{11}$ These results indicate that proximal steps of inflammatory signaling are not impaired by apoptotic cell interactions, reinforcing the view that innate apoptotic recognition engages a separate response pathway distinct from inflammatory signaling (Figure 1).

Interactions with apoptotic targets do not lead to the global repression of macrophage transcription. ${ }^{10,13}$ It may be that apoptotic transcriptional repression is exerted via a common transcriptional cofactor. Consistent with a model of coactivator sequestration or transrepression, overexpression of the transcriptional coactivator CREB-binding protein or its paralogue p300 relieves apoptotic repression. ${ }^{10}$ One possibility is that the activation of a transrepressive factor, akin to the peroxisome proliferator-activated receptor- $\gamma,{ }^{14,15}$ is responsible for selective transcriptional repression.

\section{The Specificity of Apoptotic Recognition and Response Reveals an Unconventional Innate Immunity}

The specific immunosuppressive activity of apoptotic corpses is acquired by virtually all cells undergoing apoptotic cell 
death, regardless of the cell type or the particular death stimulus. $^{8,16}$ Viable and necrotic cells do not express such inhibitory determinants. Moreover, the acquired anti-inflammatory activity persists stably in apoptotic cells, even as the cells lose membrane integrity; 'early' and 'late' apoptotic cells (with intact or compromised plasma membranes, respectively) have equivalent anti-inflammatory effect. ${ }^{8}$

By comparison, authentic necrotic cells that die with membrane rupture, although associated with inflammatory pathology in vivo, are themselves only weakly pro-inflammatory at best. $8,11,14,17,18$ Intact necrotic cells can gain potent, cell-associated immunostimulatory activity in vitro following prolonged incubation. Other manipulations, including extensive physical disruption and lysate concentration, can enhance the availability of inflammatory molecules (such as high-mobility group box 1 (HMGB1) protein and uric acid). ${ }^{19-23}$ The physiological significance of this acquired inflammatory activity is uncertain.

These results challenge a prevailing idea that apoptotic cells can devolve into necrotic corpses by persisting in the absence of engulfment, as well as the associated notion that the phagocytosis of apoptotic cells must occur prelytically so as to circumvent the inflammatory release of noxious intracellular contents from ruptured corpses. ${ }^{4,24}$ Rather, they reinforce the view that the process of apoptotic cell death, beyond assuring the elimination of inappropriate cells, confers on those dead cells a potent immunosuppressive gain of function. ${ }^{6,8-11}$

The expression of specific recognition determinants on all apoptotic cells without cell type restriction is matched by an equally ubiquitous capacity of cells of all tissue types to recognize and respond innately to apoptotic cells. The ability to ingest apoptotic cells is not restricted to professional (migratory) phagocytes, such as macrophages and dendritic cells. This phagocytic capacity has been characterized in a variety of cell types, including epithelial, endothelial, and fibroblastic cells, ${ }^{25-29}$ consistent with the clearance of dying cells in vivo by neighboring cells. ${ }^{30-32}$

This clearance by non-professional phagocytes is also linked to specific apoptotic recognition and to anti-inflammatory responsiveness, exerted primarily at the level of transcriptional repression. ${ }^{11,28,33}$ For example, the secretion of TNF $\alpha$ by epithelial cells of the mammary gland in response to LPS is suppressed by their engulfment of apoptotic cells. ${ }^{33}$ Apoptotic, but not necrotic, targets also abrogate the synthesis and release of IL- 6 by fibroblasts stimulated with IL- $1 \beta$, and they similarly affect the secretion of IL- 8 by stimulated epithelial cells. ${ }^{11}$ Thus, apoptotic responsiveness specific apoptotic recognition linked to inflammatory suppression - is an innate property ubiquitous among diverse cell types, even including non-phagocytic cells. ${ }^{11,34}$

It is even more remarkable that these innate immune interactions occur without species-specific restriction. ${ }^{9,10,35}$ Syngeneic, allogeneic, and xenogeneic targets are equally effective in triggering the full repertoire of specific apoptotic immune responses from professional and non-professional phagocyte responders. ${ }^{10,11}$ Beyond its independence from characterized innate immune signaling pathways, the absence of self-restriction marks apoptotic immunity as fundamentally distinct and unconventional. ${ }^{11}$ Apoptotic recognition

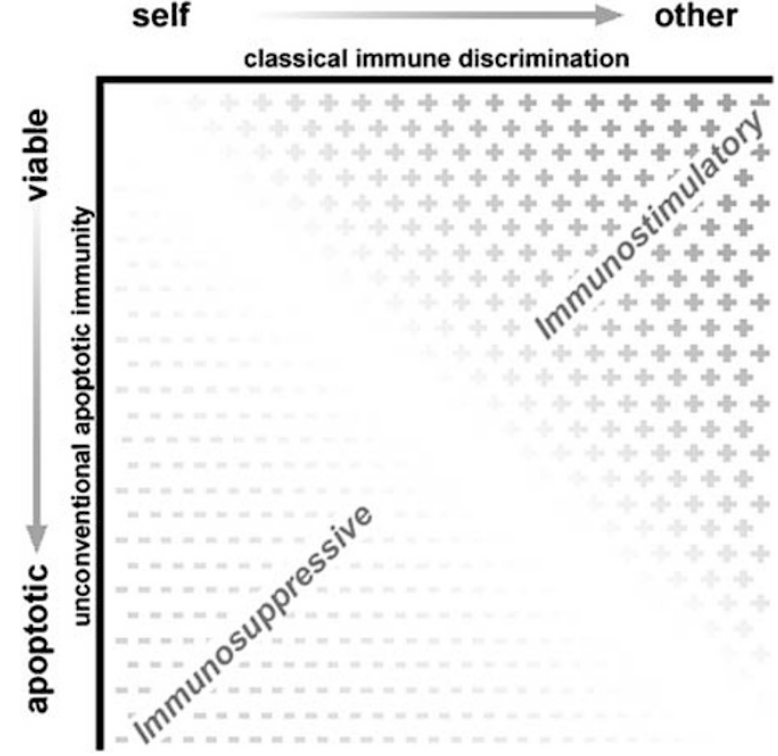

Figure 2 Two dimensions of immune recognition. Immune responsiveness is an integrated function of (at least) two independent stimulatory parameters. One dimension is well-appreciated: the recognition of that which is immunologically nonself, involving the antigen-specific receptors of $T$ and $B$ lymphocytes as well as the PAMP receptors of innate immunity. The second dimension reflects innate apoptotic immunity: the discrimination between viable and dead (or dying) apoptotic cells, without regard to self. These two dimensions are represented here along orthogonal axes. Whereas non-self agonists trigger immunostimulatory $(+++)$ responses, apoptotic agonists trigger immunosuppressive $(---)$ outcomes

determinants appear to be conserved across metazoan evolution (JE Mitchell and DS Ucker, unpublished), suggesting that this is an evolutionarily ancient arm of immunity, as well.

The immune system, both in its innate and adaptive components, is commonly viewed as a host response to pathogenic or pathological 'non-self' insults. In contrast, apoptotic recognition determinants engage an independent dimension of immune discrimination independent of selfrestriction and devoted to the maintenance of homeostasis and tolerance. These observations reveal immune responsiveness to be an integrated function of (at least) these two independent criteria of discrimination (see Figure 2). ${ }^{34}$

\section{Responses to Apoptotic Targets at Multiple Levels Serve to Exert and Maintain Apoptotic Suppression}

In parallel with the immediate-early transcriptional response, recognition of apoptotic targets triggers a characteristic set of proximal signaling events in responding macrophages, particularly involving mitogen-activated protein kinase family members. ${ }^{16,34,36}$ Apoptotic cell recognition leads to the inhibition of extracellular signal-regulated kinases 1 and 2 (ERK1/2) as well as to the activation of Jun $\mathrm{N}$-terminal kinases 1 and 2 (JNK1/2) and p38. ${ }^{16,36}$ These responses occur virtually instantaneously upon recognition of apoptotic targets. ${ }^{11,16}$ The characteristic signature of early signaling events is also elicited in non-professional phagocytes in response to apoptotic target recognition. ${ }^{11}$ In contrast, 
Table 1 Multiple levels of regulation initiate and sustain apoptotic immunosuppression

\begin{tabular}{|c|c|c|}
\hline Event & Molecular determinants & Mechanism of suppression \\
\hline Specific recognition & Not yet characterized & $\begin{array}{l}\text { Immediate-early transcriptional repression (transrepression [?]) } \\
\text { Associated signature MAPK events }\end{array}$ \\
\hline & IFN $\beta$ expression and autocrine signaling & $\begin{array}{l}\text { SOCS-dependent inhibition of PAMP receptor- and } \\
\text { IFN-dependent signal transduction }\end{array}$ \\
\hline Corpse engulfment & PS/PS opsonins, TAM receptors & \\
\hline Subsequent responses & TGF $\beta$ signaling & Production of lipid mediators \\
\hline
\end{tabular}

The profound immunosuppressive outcomes triggered by apoptotic cells involve complex sets of regulatory events. As discussed in the text, the initiation of these responses is invoked by the specific innate recognition of apoptotic cells. Secondary responses are engaged subsequently, including upon target engulfment, and can contribute to the persistence and amplification of apoptotic suppression

necrotic cell recognition leads to the activation of ERK $1 / 2$ and has no effect on JNK $1 / 2$ and p38 activation. ${ }^{16,36}$

Signature inhibition of ERK1/2 triggered by apoptotic recognition, like transcriptional repression, is dominant to ERK1/2 activation induced by PAMPs and other stimuli. ${ }^{16}$ In contrast, the effects of apoptotic recognition on JNK1/2 and p38 are not obviously different from those of PAMP stimulation and thus not associated typically with an anti-inflammatory milieu. In this context, it is notable that the failure of necrotic cells to trigger JNK1/2 and p38 activation in macrophages accords with their inability to trigger an inflammatory response. ${ }^{16}$

Secondary mechanisms, acting downstream of the initial signaling events and transcriptional repression, may sustain and enhance apoptotic immunosuppression (see Table 1). The triggered release from macrophages of potent antiinflammatory factors, including IL-10, transforming growth factor- $\beta$, and the lipid mediators prostaglandin E2 and plateletactivating factor, has been detected after prolonged interaction with apoptotic targets. ${ }^{6,9}$ These molecules may act in an autocrine fashion, or even in a paracrine manner, to disseminate inflammatory suppression. However, the generality and significance of their action in apoptotic suppression is uncertain.

Type I interferons (IFNs) also appear to be involved in later stages of apoptotic suppression. Independent of viral infection, type I IFNs, especially IFN $\beta$, are synthesized and secreted by macrophages engaged upon LPS stimulation. ${ }^{37}$ Through the action of receptor-coupled kinases, IFNs activate members of the signal transducer and activator of transcription (STAT) family, ${ }^{38}$ resulting in the expression of specific target genes involved in inflammatory responses (including several chemokines and inducible nitric oxide synthase) as well as anti-viral reactions. ${ }^{39}$ Another consequence of autocrine IFN stimulation is the production of suppressor of cytokine synthesis (SOCS) proteins, which serve as direct feedback inhibitors of the IFN signaling pathway, as well as indirect inhibitors of signaling from PAMP receptor complexes. ${ }^{40-42}$ The individual contributions of each of these responses in apoptotic suppression will require further experimentation.

\section{Phosphatidylserine as a Recognition Determinant: Potential Role at a Secondary Level}

Among the cellular components redistributed during the process of cell death, the externalization of the anionic phospholipid phosphatidylserine (PS), which appears with the reassortment of plasma membrane phospholipids, can be measured readily and has gained considerable attention as a death marker potentially linked to apoptotic clearance and suppression. ${ }^{43}$ Studies demonstrating that externalized PS targets aged erythrocytes for clearance ${ }^{44,45}$ prompted the hypothesis that similar changes on dying nucleated cells serve as flags for macrophage recognition. Further support for this view derived from observations that phospho-L-serine, PS vesicles, and even effete erythrocytes, could inhibit partially the phagocytosis of apoptotic cells. ${ }^{46,47}$

PS alone is not sufficient to serve as the determinant for specific apoptotic recognition, however. ${ }^{8}$ Neither erythrocytes nor necrotic targets, with equivalent externalized PS, trigger apoptotic-like immunosuppressive effects; conversely, apoptotic cells lacking externalized PS still are immunosuppressive. ${ }^{8,11} \mathrm{PS}$ is also exposed on viable macrophages and other cells, ${ }^{48,49}$ without triggering inflammatory suppression. Rather than a specific apoptotic determinant, externalized PS in the context of inviable cells may function as a marker for phagocytosis.

Two independent mechanisms have been identified by which PS may trigger phagocytosis. Externalized PS interacts directly with trans-membrane receptors on the phagocyte, such as BAI $1^{50}$ and $\mathrm{TIM}-4,{ }^{51}$ and it is also bound by soluble 'bridging' (so-called 'PS opsonin' or 'PS tethering') molecules. ${ }^{43}$ This latter category includes milk fat globuleepidermal growth factor 8 (MFG-E8), the product of developmental endothelial locus-1 (Del1), and the vitamin K-activated proteins growth arrest-specific factor-6 (Gas6) and protein S. Each of these tethering molecules includes a PS-binding domain and a second domain that triggers the activation of specific receptors on phagocytes. ${ }^{43}$ The phagocyte receptors for Del1 and MFG-E8 are $\alpha_{v} \beta_{5}$ and $\alpha_{v} \beta_{3}$ integrins, whereas receptors for Gas 6 and protein S comprise the Tyro3/Axl/Mer (TAM) family of receptor protein tyrosine kinases. ${ }^{43}$

Several gene targeting studies have been taken to suggest a link between the PS opsonins and inflammatory suppression. Mice lacking functional Mer, the Gas6 receptor, are impaired in monocyte function; those cells evince diminished phagocytic activity and LPS hyporesponsiveness. ${ }^{52,53}$ Correlating with the presence of unengulfed apoptotic cells, Merdeficient mice develop autoimmune pathology with increasing age. ${ }^{54}$ Similarly, elevated numbers of non-phagocytosed apoptotic corpses and aging-associated manifestations of autoimmunity are apparent in mice deficient in MFG-E8. ${ }^{55,56}$ 


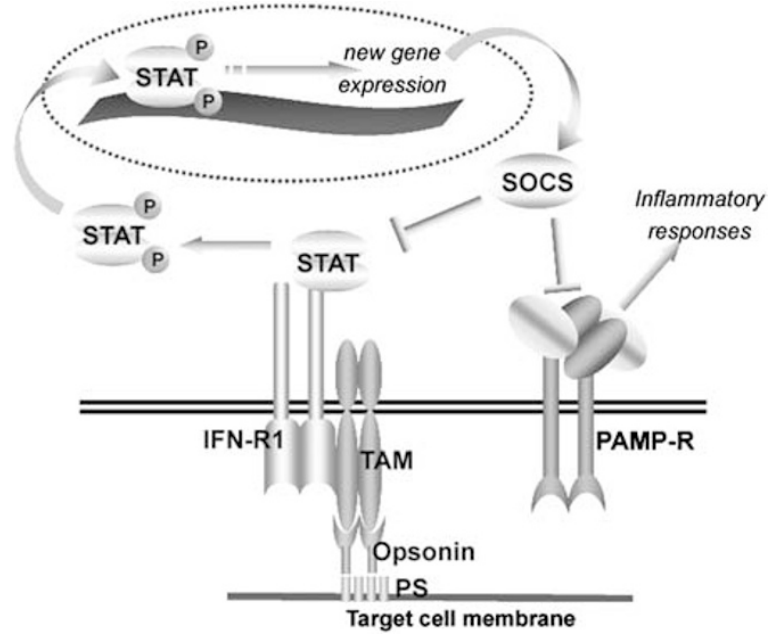

Figure 3 Secondary signaling events involved in sustaining apoptotic suppression. As discussed in the text, events subsequent to recognition can enhance apoptotic immunosuppression. Engagement of TAM receptors by PS opsonins has been demonstrated ${ }^{58}$ to lead to their interaction with the IFN receptor 1 (IFN-R1), and to STAT (especially STAT1) activation (indicated here by phosphorylation). SOCS proteins (especially SOCS1 and SOCS3) are expressed de novo in a STAT-dependent manner and these proteins serve to inhibit a variety of pro-inflammatory pathways, including cytokine and innate PAMP-R signaling complexes

It is widely accepted that the delayed clearance of apoptotic cells under these conditions is a source of stimulatory autoantigens and the trigger for autoimmune dysfunction. The underlying assumption is that, with delayed clearance, apoptotic cells become necrotic and immunostimulatory. As discussed above, this notion is refuted directly by experimental evidence. Rather, it may be that signaling from the Mer receptor kinase or from integrins engaged by MFG-E8 is normally required to sustain the immunosuppressive effects initiated upon specific apoptotic recognition. These secondary signals may arise with the engulfment of the apoptotic corpse, and in the absence of engulfment, the lack of secondary suppressive effects (as opposed to unengulfed apoptotic cells per $\mathrm{se}^{57}$ ) contributes to immune pathology. ${ }^{34}$

Consistent with this developing view of a modulatory network to enhance and sustain apoptotic immunosuppression (see Figure 3), Rothlin et al. ${ }^{58}$ have documented recently that when TAM receptors are activated by their ligands Gas6 and/or protein $\mathrm{S}$, they act as negative regulators of proinflammatory signaling pathways via the induction of SOCS proteins. Mechanistically, TAM receptors appear to interact functionally with IFN type 1 receptors, leading to selective STAT1-dependent expression of SOCS proteins and upregulation of the TAM receptors themselves. ${ }^{58}$

Further work is needed to explore the consequences of TAM engagement by authentic opsonized cellular targets (as distinct from their purified ligands). It will be important to evaluate potential differences between apoptotic and other dead cells with regard to their accessibility for opsonin binding and the resulting density, conformation, and tethering activity of bound opsonins. One important and unexpected prediction that follows from this model is that non-apoptotic targets with externalized PS (including necrotic cells and perhaps effete erythrocytes) also might be effective in triggering this second tier of immunosuppressive activity.

\section{Tipping the Balance of Apoptotic Suppression?}

In addition to the PS opsonins, other tethering molecules with distinctly pro-inflammatory activities have been implicated in apoptotic cell clearance. It is reasonable to imagine that dominant-acting immunosuppressive signaling elicited upon apoptotic recognition overrides any inflammatory signal that might be triggered through the additional involvement of PAMP recognition, complement/collectin, or other innate immune receptors. ${ }^{24,59-63}$ Still, the involvement of immunostimulatory molecules in an immunosuppressive process is paradoxical.

In this context, it is intriguing to consider a recent study, in which it was found that cells of a particular tumor cell line, when induced by anthracyclins (e.g. doxorubicin) to undergo an apoptotic death, unexpectedly become relatively immunogenic. ${ }^{64}$ Further work has suggested that a target cell-derived nuclear protein, HMGB1, is released from the dead cells and serves as an immune adjuvant via PAMP receptor signaling. ${ }^{65}$ This is surprising since, as discussed above, apoptotic suppression overrides PAMP stimulation. ${ }^{10,11}$ It will be critical to evaluate more fully the relative immunogenic phenotype of these dead cells and explore whether this reflects a loss of suppressive function or a novel gain of activity.

A more general evaluation of the immunostimulatory status of apoptotic cells is also worthwhile. While a number of reports have suggested that apoptotic cells can serve as a source of immunostimulatory antigens, ${ }^{21,65-68}$ others have reported an absence of apoptotic immunogenicity. ${ }^{69-71}$ Studies in which the relative efficacies of apoptotic and necrotic targets as sources of immunogenic antigens were compared rigorously ${ }^{21,68}$ suggest that apoptotic cells are, at best, only poorly immunogenic. The direct examination of the functional status of antigen-presenting dendritic cells following their interaction with apoptotic targets, as measured by the levels of expression of costimulatory molecules (CD80 and CD86) and the ability to stimulate antigen-specific T-cell responsiveness, also indicates that apoptotic cells suppress antigen-presenting activity generally. ${ }^{70}$ While it may be possible experimentally to compel an antigenic immune response from apoptotic cells, these studies call into question the physiological (or pathophysiological) significance of such a response.

\section{Prospects}

Apoptotic cells potently trigger an extensive array of immunosuppressive effects. Innate apoptotic immunity is remarkable as a ubiquitous and unconventional dimension of immune responsiveness. In this regard, the apoptotic cell death process functions unexpectedly in homeostasis as a mechanism for the maintenance of tolerance and the attenuation of inflammation. The full picture of its critical molecular constituents and the relevant mechanisms of complex regulation is only just beginning to emerge.

Fundamental issues concerning innate apoptotic immunity remain to be explored, none more important than the characterization of specific recognition determinants on 
apoptotic cells and the corresponding receptors on professional phagocytes and other responders. It is tantalizing to consider that specific recognition determinants may reside among the numerous autoantigens known to be presented $^{72,73}$ on the apoptotic cell surface.

It is also important to dissect further the multiple levels of regulation at which immunosuppression is exerted, including primary transcriptional repression. The lessons of apoptotic immunity prompts question about the effects of other modes of death, especially including autophagy. The consequences of autophagic cell death on responder cells currently remain unresolved. $^{74,75}$

Finally, a deeper understanding of the relevant molecules and immunosuppressive pathways employed physiologically by apoptotic cells may reveal new biomarkers and targets for immunological control, with great potential for intervention in cases of pathological inflammation and immune response.

1. Clarke PG, Clarke S. Nineteenth century research on naturally occurring cell death and related phenomena. Anat Embryol 1996; 193: 81-99.

2. Metchnikoff E. Leçons sur la pathologie comparée de l'inflammation. Translation of 'Leçons sur la pathologie comparée de I'inflammation'. New York: Dover Publications, 1891

3. Kerr JFR, Wyllie AH, Currie AR. Apoptosis: a basic biological phenomenon with wideranging implications in tissue kinetics. Br J Cancer 1972; 26: 239-256.

4. Savill JS, Wyllie AH, Henson JE, Walport MJ, Henson PM, Haslett C. Macrophage phagocytosis of aging neutrophils in inflammation: programmed cell death in the neutrophil leads to its recognition by macrophages. J Clin Invest 1989; 83: 865-875.

5. Meagher LC, Savill JS, Baker A, Fuller RW, Haslett C. Phagocytosis of apoptotic neutrophils does not induce macrophage release of thromboxane $B_{2}$. J Leuk Biol 1992; 52 269-272.

6. Fadok VA, Bratton DL, Konowal A, Freed PW, Westcott JY, Henson PM. Macrophages that have ingested apoptotic cells in vitro inhibit proinflammatory cytokine production through autocrine/paracrine mechanisms involving TGF- $\beta$, PGE2, and PAF. J Clin Invest 1998; 101: 890-898

7. Hughes J, Liu Y, Damme JV, Savill J. Human glomerular mesangial cell phagocytosis of apoptotic neutrophils. J Immunol 1997; 158: 4389-4397.

8. Cocco RE, Ucker DS. Distinct modes of macrophage recognition for apoptotic and necrotic cells are not specified exclusively by phosphatidylserine exposure. Mol Biol Cell 2001; 12 : 919-930.

9. Voll RE, Herrmann M, Roth EA, Stach C, Kalden JR, Girkontaite I. Immunosuppressive effects of apoptotic cells. Nature 1997; 390: 350-351.

10. Cvetanovic M, Ucker DS. Innate immune discrimination of apoptotic cells: repression of proinflammatory macrophage transcription is coupled directly to specific recognition. $\mathrm{J}$ Immunol 2004; 172: 880-889.

11. Cvetanovic M, Mitchell JE, Patel V, Avner BS, Su Y, van der Saag PT et al. Specific recognition of apoptotic cells reveals a ubiquitous and unconventional innate immunity. J Biol Chem 2006; 281: 20055-20067.

12. Akira S, Takeda K, Kaisho T. Toll-like receptors: critical proteins linking innate and acquired immunity. Nat Immunol 2001; 2: 675-680.

13. Tassiulas I, Park-Min K-H, Hu Y, Kellerman L, Mevorach D, Ivashkiv LB. Apoptotic cells inhibit LPS-induced cytokine and chemokine production and IFN responses in macrophages. Hum Immunol 2007; 68: 156-164.

14. Johann AM, von Knethen A, Lindemann D, Brüne B. Recognition of apoptotic cells by macrophages activates the peroxisome proliferator-activated receptor- $\gamma$ and attenuates the oxidative burst. Cell Death Differ 2006; 13: 1533-1540.

15. Majái G, Sarang Z, Csomós K, Zahuczky G, Fésüs L. PPAR $\gamma$-dependent regulation of human macrophages in phagocytosis of apoptotic cells. Eur J Immunol 2007; 37: 1343-1354.

16. Patel VA, Longacre A, Hsiao K, Fan H, Meng F, Mitchell JE et al. Apoptotic cells, at all stages of the death process, trigger characteristic signaling events that are divergent from and dominant over those triggered by necrotic cells: implications for the delayed clearance model of autoimmunity. J Biol Chem 2006; 281: 4663-4670.

17. Brouckaert G, Kalai M, Krysko DV, Saelens X, Vercammen D, Ndlovu M et al. Phagocytosis of necrotic cells by macrophages is phosphatidylserine-dependent and does not induce inflammatory cytokine production. Mol Biol Cell 2004; 15: 1089-1100.

18. Hirt UA, Leist M. Rapid, noninflammatory and PS-dependent phagocytic clearance of necrotic cells. Cell Death Differ 2003; 10: 1156-1164.

19. Scaffidi $P$, Misteli T, Bianchi ME. Release of chromatin protein HMGB1 by necrotic cells triggers inflammation. Nature 2002; 418: 191-195.

20. Shi Y, Evans JE, Rock KL. Molecular identification of a danger signal that alerts the immune system to dying cells. Nature 2003; 425: 516-521.
21. Sauter B, Albert ML, Francisco L, Larsson M, Somersan S, Bhardwaj N. Consequences of cell death: exposure to necrotic tumor cells, but not primary tissue cells or apoptotic cells, induces the maturation of immunostimulatory dendritic cells. J Exp Med 2000; 191 : 423-434

22. Li M, Carpio DF, Zheng Y, Bruzzo P, Singh V, Ouaaz F et al. An essential role of the $\mathrm{NF}-\kappa \mathrm{B} /$ Toll-like receptor pathway in induction of inflammatory and tissue-repair gene expression by necrotic cells. J Immunol 2001; 166: 7128-7135.

23. Chen C-J, Kono H, Golenbock D, Reed G, Akira S, Rock KL. Identification of a key pathway required for the sterile inflammatory response triggered by dying cells. Nat Med 2007; 13: $851-856$.

24. Stern M, Savill J, Haslett C. Human monocyte-derived macrophage phagocytosis of senescent eosinophils undergoing apoptosis: mediation by $\alpha_{v} \beta_{3} / \mathrm{CD} 36 /$ thrombospondin recognition mechanism and lack of phlogistic response. Am J Pathol 1996; 149: 911-921.

25. Fadok VA, Bratton DL, Rose DM, Pearson A, Ezekowitz RAB, Henson PM. A receptor for phosphatidylserine-specific clearance of apoptotic cells. Nature 2000; 405: 85-90.

26. Albert ML, Kim Jl, Birge RB. $\alpha_{v} \beta_{5}$ integrin recruits the Crkll-Dock180-Rac1 complex for phagocytosis of apoptotic cells. Nat Cell Biol 2000; 2: 899-905.

27. Brugnera E, Haney L, Grimsley C, Lu M, Walk SF, Tosello-Trampont AC et al. Unconventional Rac-GEF activity is mediated through the Dock180-ELMO complex. Nat Cell Biol 2002; 4: 574-582.

28. Mitchell JE, Cvetanovic M, Tibrewal N, Patel V, Colamonici OR, Li MO et al. The presumptive phosphatidylserine receptor is dispensable for innate anti-inflammatory recognition and clearance of apoptotic cells. J Biol Chem 2006; 281: 5718-5725.

29. Chen Q, Stone PR, McCowan LM, Chamley LW. Phagocytosis of necrotic but not apoptotic trophoblasts induces endothelial cell activation. Hypertension 2006; 47: 116-121.

30. Parnaik R, Raff MC, Scholes J. Differences between the clearance of apoptotic cells by professional and non-professional phagocytes. Curr Biol 2000; 10: 857-860.

31. Wood W, Turmaine M, Weber R, Camp V, Maki RA, McKercher SR et al. Mesenchymal cells engulf and clear apoptotic footplate cells in macrophageless PU.1 null mouse embryos. Development 2000; 127: 5245-5252.

32. Nandrot EF, Kim Y, Brodie SE, Huang X, Sheppard D, Finnemann SC. Loss of synchronized retinal phagocytosis and age-related blindness in mice lacking $\alpha \mathrm{v} \beta 5$ integrin. $J$ Exp Med 2004; 200: 1539-1545

33. Monks J, Rosner D, Geske FJ, Lehman L, Hanson L, Neville MC et al. Epithelial cells as phagocytes: apoptotic epithelial cells are engulfed by mammary alveolar epithelial cells and repress inflammatory mediator release. Cell Death Differ 2005; 12: 107-114.

34. Patel VA, Longacre-Antoni A, Cvetanovic M, Lee DJ, Feng L, Fan $\mathrm{H}$ et al. The affirmative response of the innate immune system to apoptotic cells. Autoimmunity 2007; 40: 274-280.

35. McDonald PP, Fadok VA, Bratton D, Henson PM. Transcriptional and translational regulation of inflammatory mediator production by endogenous TGF- $\beta$ in macrophages that have ingested apoptotic cells. J Immunol 1999; 163: 6164-6172.

36. Reddy SM, Hsiao KH, Abernethy VE, Fan H, Longacre A, Lieberthal W et al. Phagocytosis of apoptotic cells by macrophages induces novel signaling events leading to cytokineindependent survival and inhibition of proliferation: activation of Akt and inhibition of extracellular signal-regulated kinases 1 and 2. J Immunol 2002; 169: 702-713.

37. Toshchakov V, Jones BW, Perera P-Y, Thomas K, Cody MJ, Zhang S et al. TLR4, but not TLR2, mediates IFN- $\beta$-induced STAT1 $\alpha / \beta$-dependent gene expression in macrophages. Nat Immunol 2002; 3: 392-398.

38. Platanias LC. Mechanisms of type-I- and type-II-interferon-mediated signalling. Nat Rev Immunol 2005; 5: 375-386

39. Decker T, Stockinger S, Karaghiosoff M, Muller M, Kovarik P. IFNs and STATs in innate immunity to microorganisms. J Clin Invest 2002; 109: 1271-1277.

40. Kinjyo I, Hanada T, Inagaki-Ohara K, Mori H, Aki D, Ohishi M et al. SOCS1/JAB is a negative regulator of LPS-induced macrophage activation. Immunity 2002; 17: 583-591.

41. Nakagawa R, Naka T, Tsutsui H, Fujimoto M, Kimura A, Abe T et al. SOCS-1 participates in negative regulation of LPS responses. Immunity 2002; 17: 677-687.

42. Baetz A, Frey M, Heeg K, Dalpke AH. Suppressor of cytokine signaling (SOCS) proteins indirectly regulate toll-like receptor signaling in innate immune cells. J Biol Chem 2004; 279 : 54708-54715

43. Wu Y, Tibrewal N, Birge RB. Phosphatidylserine recognition by phagocytes: a view to a kill. Trends Cell Biol 2006; 16: 189-197.

44. Schroit AJ, Madsen JW, Tanaka Y. In vitro recognition and clearance of red blood cells containing phosphatidylserine in their plasma membranes. J Biol Chem 1985; 260: 5131-5138.

45. McEvoy L, Williamson P, Schlegel RA. Membrane phospholipid asymmetry as a determinant of erythrocyte recognition by macrophages. Proc Natl Acad Sci USA 1986; 83: 3311-3315

46. Fadok VA, Voelker DR, Campbell PA, Cohen JJ, Bratton DL, Henson PM. Exposure of phosphatidylserine on the surface of apoptotic lymphocytes triggers specific recognition and removal by macrophages. J Immunol 1992; 148: 2207-2216.

47. Pradhan D, Krahling S, Williamson $P$, Schlegel RA. Multiple systems for recognition of apoptotic lymphocytes by macrophages. Mol Biol Cell 1997; 8: 767-778.

48. Marguet D, Luciani MF, Moynault A, Williamson P, Chimini G. Engulfment of apoptotic cells involves the redistribution of membrane phosphatidylserine on phagocyte and prey. Nat Cell Biol 1999; 1: 454-456. 
49. Callahan MK, Halleck MS, Krahling S, Henderson AJ, Williamson P, Schlegel RA Phosphatidylserine expression and phagocytosis of apoptotic thymocytes during differentiation of monocytic cells. J Leuk Biol 2003; 74: 846-856.

50. Park D, Tosello-Trampont AC, Elliott MR, Lu M, Haney LB, Ma Z et al. BAl1 is an engulfment receptor for apoptotic cells upstream of the ELMO/Dock180/Rac module. Nature 2007; 450: 430-434.

51. Miyanishi M, Tada K, Koike M, Uchiyama Y, Kitamura T, Nagata S. Identification of Tim4 as a phosphatidylserine receptor. Nature 2007; 450: 435-439.

52. Camenisch TD, Koller BH, Earp HS, Matsushima GK. A novel receptor tyrosine kinase Mer, inhibits TNF- $\alpha$ production and lipopolysaccharide-induced endotoxic shock. J Immunol 1999; 162: 3498-3503.

53. Scott RS, McMahon EJ, Pop SM, Reap EA, Caricchio R, Cohen PL et al. Phagocytosis and clearance of apoptotic cells is mediated by MER. Nature 2001; 411: 207-211.

54. Cohen PL, Caricchio R, Abraham V, Camenisch TD, Jennette JC, Roubey RAS et al. Delayed apoptotic cell clearance and lupus-like autoimmunity in mice lacking the c-mer membrane tyrosine kinase. J Exp Med 2002; 196: 135-140.

55. Hanayama R, Tanaka M, Miyasaka K, Aozasa K, Koike M, Uchiyama Y et al. Autoimmune disease and impaired uptake of apoptotic cells in MFG-E8-deficient mice. Science 2004 304: $1147-1150$

56. Asano K, Miwa M, Miwa K, Hanayama R, Nagase H, Nagata $S$ et al. Masking of phosphatidylserine inhibits apoptotic cell engulfment and induces autoantibody production in mice. J Exp Med 2004; 200: 459-467.

57. Savill J, Dransfield I, Gregory C, Haslett C. A blast from the past: clearance of apoptotic cells regulates immune responses. Nat Rev Immunol 2002; 2: 965-975.

58. Rothlin CV, Ghosh S, Zuniga El, Oldstone MB, Lemke G. TAM receptors are pleiotropic inhibitors of the innate immune response. Cell 2007; 131: 1124-1136.

59. Botto M, Dell'Agnola C, Bygrave AE, Thompson EM, Cook HT, Petry F et al. Homozygous C1q deficiency causes glomerulonephritis associated with multiple apoptotic bodies. Nat Genet 1998; 19: 56-59.

60. Mevorach D, Mascarenhas JO, Gershov D, Elkon KB. Complement-dependent clearance of apoptotic cells by human macrophages. J Exp Med 1998; 188 2313-2320.

61. Gardai SJ, McPhillips KA, Frasch SC, Janssen WJ, Starefeldt A, Murphy-Ullrich JE et al. Cell-surface calreticulin initiates clearance of viable or apoptotic cells through transactivation of LRP on the phagocyte. Cell 2005; 123: 321-334.
62. Nauta AJ, Trouw LA, Daha MR, Tijsma O, Nieuwland R, Schwaeble WJ et al. Direct binding of $\mathrm{C} 1 \mathrm{q}$ to apoptotic cells and cell blebs induces complement activation. Eur J Immunol 2002; 32: 1726-1736.

63. Devitt A, Moffatt OD, Raykundalia C, Capra JD, Simmons DL, Gregory CD. Human CD14 mediates recognition of phagocytosis of apoptotic cells. Nature 1998; 392: 505-509.

64. Obeid M, Tesniere A, Ghiringhelli F, Fimia GM, Apetoh L, Perfettini J-L et al. Calreticulin exposure dictates the immunogenicity of cancer cell death. Nat Med 2007; 13: 54-61.

65. Apetoh L, Ghiringhelli F, Tesniere A, Obeid M, Ortiz C, Criollo A et al. Toll-like receptor 4-dependent contribution of the immune system to anticancer chemotherapy and radiotherapy. Nat Med 2007; 13: 1050-1059.

66. Albert ML, Sauter B, Bhardwaj N. Dendritic cells acquire antigen from apoptotic cells and induce class 1-restricted CTLs. Nature 1998; 392: 86-89.

67. Nouri-Shirazi M, Banchereau J, Bell D, Burkeholder S, Kraus ET, Davoust J et al. Dendritic cells capture killed tumor cells and present their antigens to elicit tumor-specific immune responses. J Immunol 2000; 165: 3797-3803.

68. Ronchetti A, Rovere P, lezzi G, Galati G, Heltai S, Protti MP et al. Immunogenicity of apoptotic cells in vivo: role of antigen load, antigen-presenting cells, and cytokines. $J$ Immunol 1999; 163: 130-136.

69. Liu K, lyoda T, Saternus M, Kimura Y, Inaba K, Steinman RM. Immune tolerance after delivery of dying cells to dendritic cells in situ. J Exp Med 2002; 196: 1091-1097.

70. Stuart LM, Lucas M, Simpson C, Lamb J, Savill J, Lacy-Hulbert A. Inhibitory effects of apoptotic cell ingestion upon endotoxin-driven myeloid dendritic cell maturation. J Immunol 2002; 168: 1627-1635.

71. Blander JM, Medzhitov R. Regulation of phagosome maturation by signals from toll-like receptors. Science 2004; 304: 1014-1018.

72. Cocca BA, Cline AM, Radic MZ. Blebs and apoptotic bodies are B cell autoantigens $J$ Immunol 2002; 169: 159-166.

73. Casciola-Rosen LA, Anhalt G, Rosen A Autoantigens targeted in systemic lupus erythematosus are clustered in two population of surface structures on apoptotic keratinocytes. J Exp Med 1994; 179: 1317-1339.

74. Degenhardt K, Mathew R, Beaudoin B, Bray K, Anderson D, Chen G et al. Autophagy promotes tumor cell survival and restricts necrosis, inflammation, and tumorigenesis. Cancer Cell 2006; 10: 51-64.

75. Petrovski G, Zahuczky G, Majái G, Fésüs L. Phagocytosis of cells dying through autophagy evokes a pro-inflammatory response in macrophages. Autophagy 2007; 3: 509-511. 